Article

\title{
Assessing the Impact of Participatory Extension Programme Membership on Farm Business Performance in Northern Ireland
}

\author{
Adewale H. Adenuga ${ }^{1, *(\mathbb{D}}$, Claire Jack ${ }^{1}$, Austen Ashfield ${ }^{1}$ and Michael Wallace ${ }^{2} \mathbb{D}$ \\ 1 Economics Research Branch, Agri-Food and Biosciences Institute, 18a Newforge Lane, Belfast BT9 5PX, UK; \\ claire.jack@afbini.gov.uk (C.J.); austen.ashfield@afbini.gov.uk (A.A.) \\ 2 School of Agriculture and Food Science, University College Dublin, 4 Dublin, Ireland; michael.wallace@ucd.ie \\ * Correspondence: adewale.adenuga@afbini.gov.uk
}

Citation: Adenuga, A.H.; Jack, C.; Ashfield, A.; Wallace, M. Assessing the Impact of Participatory Extension Programme Membership on Farm Business Performance in Northern Ireland. Agriculture 2021, 11, 949. https://doi.org/10.3390/ agriculture11100949

Academic Editor: Cornelia Flora

Received: 27 August 2021

Accepted: 26 September 2021

Published: 30 September 2021

Publisher's Note: MDPI stays neutral with regard to jurisdictional claims in published maps and institutional affiliations.

Copyright: (c) 2021 by the authors. Licensee MDPI, Basel, Switzerland. This article is an open access article distributed under the terms and conditions of the Creative Commons Attribution (CC BY) license (https:/ / creativecommons.org/licenses/by/ $4.0 /)$.

\begin{abstract}
This paper evaluates the impact of membership of the Business Development Groups (BDG), a participatory extension programme in Northern Ireland on the economic performance of participating farmers for dairy and sheep enterprise groups. The study employs the conditional difference-in-differences approach which combines a non-parametric matching estimator with a difference-in-differences analytical technique to obtain a credible best-estimates of the causal effect of BDG membership on farmers' economic performance assuming that BDG participation is as good as random after controlling for observable farm characteristics and that the parallel trends assumption holds between BDG participants and non-participants. The results of the analyses showed that membership in the BDG programme has a statistically significant impact on the economic performance of participating farmers. Specifically, the results showed that farmers who are members of the dairy and sheep BDGs increased their gross margin by $£ 109.10$ and $£ 17.10$ per head respectively compared to farmers that are non-members of the BDGs. The results of the study provide robust evidence to inform policy development around the area of participatory extension programmes. It also supports the design of efficient agricultural education and extension systems that incorporates the ideas of the farmers themselves through peer-to-peer learning thereby maximising the economic and social benefits accruable from such programmes.
\end{abstract}

Keywords: impact assessment; participatory extension; conditional difference-in-differences; matching; Business Development Groups; Northern Ireland

\section{Introduction}

Effective agricultural extension programmes can increase the productivity and innovation capacity of farming businesses by helping farmers as managers to augment their skills and knowledge as well as embrace new technologies and best practices [1,2]. However, the extent to which farmers benefit from such extension programmes depends largely on the design of the programme. Agricultural extension service programmes have to be designed with the capacity to improve farm performance and connect emerging research to on-farm practices [3-7]. The international literature commonly identifies four major strands of agricultural extension methods: linear technology transfer, one-to-one advice, structured education and training, and participatory extension methods [4,8,9]. National advisory programmes around the world have tended to adopt a range and combination of these methods to fulfil their farm-level extension remit.

Northern Ireland has historically delivered extension services on an advisor to farm, one-to-one basis using a top-down approach [1]. However, this approach has limitations regarding the extent of its coverage to farmers and its inability to account for the current, more complex agricultural production environment which requires more responsive and innovative approaches. In a bid to improve economic performance at the farm-level through 
fostering the competitiveness of agriculture and ensuring the sustainable management of resources, the Northern Ireland College of Agriculture, Food and Rural Enterprise (CAFRE) adopted, in March 2016, a new approach to advisory service provision for farmers namely; Business Development Groups (BDG's). The BDG is a knowledge transfer scheme that forms part of a wider programme, the Farm Business Improvement Scheme (FBIS), partfunded by the EU through Pillar II of the Northern Ireland Rural Development Programme 2014-2020 [10].

The BDG programme employs a group approach aimed at improving the performance of farm businesses through facilitated 'peer-to-peer' learning to encourage the fostering of knowledge capital and knowledge exchange between actors. Farmers participating in the scheme have farm key performance indicators recorded and benchmarked every year to identify areas for potential improvement for the period for which they are members of the BDGs. Participating BDG members maintain an active business development plan, attend training events, and share benchmarking information with other group members. Each farmer also hosts a group training event on their farm during the lifetime of the scheme. Interactions are held under the guidance of a facilitator to bring in new ideas and foster innovation, particularly around the use of new technologies. This gives the farmers improved access to local and expert knowledge, as well as well-functioning social networks that promote rural innovations. The farmers meet formally six to eight times a year, providing them with an opportunity to talk about their own farm business issues, including responses to wider market, policy and technology drivers. The allocation to groups is by main farm enterprise and farm location [11].

As with other publicly funded programmes, evaluating the scheme's effectiveness in meeting defined objectives is of pivotal consideration. This is particularly around quantifying the 'value for money' aspect of the scheme while providing robust evidence for future programme developments. Specifically, the objective of this study is to obtain a credible best-estimate of the impact of membership of the Northern Ireland farmers Business Development Groups (BDGs) on-farm gross margin for the dairy and sheep enterprise groups.

This study contributes to the existing literature by analysing the impact of membership of participatory extension groups on farm income for different enterprise groups. This is essential as the type and mode of operation of the participatory extension group which a farmer is a member of could affect the benefits accruable from the membership of such groups. Previous studies have focused on only one type of enterprise, for example, Hennessy and Heanue [3] and Läpple, Hennessy and Newman [5]. Secondly, unlike previous studies, we take advantage of both the longitudinal nature of the FBIS dataset and the Northern Ireland Farm Business Survey (NBS) to estimate the impact of membership of the BDG programme on-farm economic performance making use of the conditional difference-in-differences approach which previously has had limited application in the agricultural extension and education evaluation literature. The methodology addresses the problem of endogeneity by combining a non-parametric matching approach with a difference-in-differences analytical technique to facilitate us obtaining a credible estimate of the impact of BDG membership in a nonexperimental context.

The results of the study will provide evidence to inform policy development around the area of participatory extension programmes.

The remaining sections of this paper are organised as follows: Section 2 provides a comprehensive literature review while Section 3 describes the methodology. Section 4 explains the nature of the data used and describes the characteristics of the BDG groups. The results and discussion are presented in Section 5 and finally, Section 6 concludes the paper.

\section{Literature Review}

The goal of programme evaluation in an economic context is to assess the value of the participant's outcome from membership of the programme compared to the counterfactual 
outcome, that is, if they had not participated in the programme. In practice, this is not a trivial task. The fundamental evaluation problem arises because it is not possible to observe the same person in both states (i.e., participation and non-participation) nor at the same time $[12,13]$. As a result, the programme evaluation literature has advanced methodological solutions to address these challenges in identifying causal policy effects.

Generally, there are two main approaches to measuring programme impacts: experimental and non-experimental methods. The experimental approach has the advantage of having a control group that has the same distributions of both observed and unobserved characteristics as the treatment group such that, the treatment effect can be estimated from the mean difference in outcome between the treated and the control group [14]. However, the approach is usually expensive, time-consuming and (especially in Europe) considered to be non-ethical $[12,14-17]$. On the other hand, the non-experimental approach is less expensive and less intrusive and can, in fact, be the only alternative for some questions of interest, for example, when enrolment into a programme is voluntary as is the case with the BDG scheme [12].

Despite its advantages, a significant obstacle to using the non-experimental approach is the econometric issue of endogeneity (omitted variable bias, measurement error, and self-selection) inherent in non-experimental evaluations [18-20]. For example, participation in the BDG programme is voluntary such that the decision to participate in the programme is likely to be influenced by characteristics that are in turn related to farm performance. The implication of this is that aside from their participation status, there are systematic differences between farmers in the treated (farmers that participate in the BDG programme) and the control groups (farmers that do not participate in the BDG programme) either in terms of observed or unobserved characteristics. For example, better educated and/or younger farmers with greater access to information may be more inclined to join a BDG compared to less educated and/or older farmers. Farmers may also, as previous studies suggest, be more likely to adopt technologies they are exposed to as a result of their membership of and participation in a group and this subsequently impacts their farm performance $[5,6,21]$. Therefore, any attempt to estimate the mean impact of the programme as the mean difference between the treated and the control group will yield biased results [22].

Previous research on the impact of membership of participatory extension programmes on-farm performance included studies by Hennessy and Heanue [3] who assessed the effect of membership of dairy participatory extension groups on technology adoption and farm profit in Ireland, using a multiple regression technique on cross-sectional data. They concluded from their study that membership of participatory extension groups increases technology adoption and farm profit. However, a limitation of this study is that it omitted accounting for selection bias and other confounding factors that could result in biased estimates of the programme impact $[23,24]$. Some studies have tried to address this endogeneity issue by employing other approaches. Examples of such studies include Läpple, Hennessy and Newman [5] who employed the endogenous switching regression model to quantify the benefit of membership in a dairy participatory extension group in Ireland. However, because the switching model relies on conditional expectations of impact based on non-participation in the extension programme compared with the actual results; it implies that it is based on the hypothetical case of an outcome [20]. Läpple and Hennessy [25] also analysed the impact of incentives to participate in an extension programme in Ireland using the propensity score matching (PSM) methodology. They found that farmers who joined the dairy participatory extension group when no incentive was given significantly improved their farm performance in terms of gross margins and yields compared to farmers who joined the group when financial incentives were included. Similarly, Tamini [6] employed the propensity score matching (PSM) approach to evaluate the impact of agri-environmental extension activities on best management practices in relation to environmental goods by farmers in the province of Quebec, Canada. The results showed that participation in extension services and advisory clubs positively impacts the probability of adopting best management practices. Although the use of the propensity 
score matching can account for selection bias due to observed differences, reducing the conventional measure of bias substantially, it does not entirely eliminate it as it relies on a number of decisive steps based on the quality of data and underpinning assumptions often involving a trade-off between bias and efficiency $[14,16,20,26]$. The approach also does not correct for bias resulting from differences in unobserved characteristics.

The use of instrumental variable techniques by Cawley, O'Donoghue, Heanue, Hilliard, Sheehan and Stefanou [20] proved to be an advancement over the PSM or endogenous switching regression approach as it is characterised by high internal validity ensuring that endogeneity concerns are addressed. The approach can take into consideration observed and unobserved factors correcting for selection bias in estimating the impact of the programme. In their study, they showed that membership of participatory extension programmes significantly increased farm income and that OLS estimates underestimated the impact. However, the use of the instrumental variable technique requires the inclusion of appropriate selection instruments that affect the probability to participate but do not affect the outcome [27]. Valid instruments are usually difficult to find and the fact that the instruments affect the dependent variable only through the endogenous regressor implies that it measures only the average causal effect for the entities affected by the instrument (Local Average Treatment Effect, (LATE)) rather than the average treatment effect (ATE) [28].

In this paper, we address the problem of endogeneity without relying on the validity of an instrument to estimate the causal effect of the membership of the BDG programme on farm income. Recent literature has emphasized the strength of combining a difference-indifference (DID) approach with propensity score matching (PSM) [29]. Examples of such studies include Davis et al. [30] where they employed a combination of matching estimators (propensity score matching and covariate matching) and the difference-in-difference approach to evaluate the impact of farmer field school (FFS) project on poverty alleviation and agricultural productivity in East Africa between 1999 and 2008. A similar methodology was also employed by Rose [31] to systematically evaluate the impact of active labour market policy (ALMP) schemes on the well-being of the unemployed. Bakucs et al. [32] measured the effect of rural development support on the well-being of Hungarian regions between 2008 and 2013 using the same methodology. The methodology is also employed by Su, et al. [33] to evaluate the effect of urban and rural resident medical insurance scheme (URRMI) on the utilisation of medical services by urban and rural residents in the four pilot provinces in China. Udagawa, Hodge and Reader [29] employed the methodology to examine the impact of participation in the Entry Level Stewardship (ELS) scheme on cereal farm incomes in eastern England.

\section{Materials and Methods}

In this study, we analysed the impact of BDG membership on economic performance, this is measured based on farm-level gross margins for dairy and sheep groups using the conditional difference-in-differences approach. The methodology combines a nonparametric score matching estimator with a difference-in-differences (DiD) estimator. In the following section, we explain our estimation strategy in detail and provide the rationale for utilising our chosen approach.

\subsection{Estimation Strategy}

To measure the impact of membership of the BDG programme, our estimation strategy follows the framework developed by Rubin [34]. Taking $Y_{i}^{1}$ as the income of a farmer who joined the BDG programme and $Y_{i}^{0}$ as the income of the farmer if he or she had not joined the BDG programme. The overall programme impact of membership of the BDG programme can be identified as the average treatment effect on the treated units. This can be obtained as the difference in farm income $(\Delta \mathrm{Y})$ between the income of farmers 
in the BDG programme $\left(Y_{i}^{1}\right)$ and income of the farmers had they not joined the BDG programme $\left(Y_{i}^{0}\right)$

$$
\Delta \mathrm{Y}=\frac{1}{N_{1}} \sum_{i} \Delta Y_{i}
$$

where $\Delta Y_{i}=Y_{i}^{1}-Y_{i}^{0}$.

$Y_{i}^{1}$ and $Y_{i}^{0}$ as already defined, represent the income of the farmer $i$ if he or she is in a BDG group $(D=1)$ and if not in the BDG group $(D=0)$ respectively while $N_{1}$ is the number of farmers in the BDG group under consideration. However, $Y_{i}^{0}$ cannot be observed directly from the data for the farmers in the BDG programme (counterfactual outcome). To estimate the average treatment effect of membership of a BDG group, the unobservable counterfactual outcome will have to be replaced by a proxy that can be measured. The literature identifies two ways in which to achieve this. The first is to explore the situation of the farmers before and after they join the BDG programme and the other is to identify a control group consisting of farmers who are not members of the BDG programme based on the crucial "parallel trend assumption". However, given that the farm business entity might be subjected to changes in the policy environment or could improve productivity over the observation period, the before-and-after identifying assumption in itself might result in biased impact estimates [29,35]. On the other hand, the farmers who are members of the BDG programme and those that are not members are likely to differ in their characteristics which might influence their farm economic performance. As a result, the mean of the outcome variable of non-members of the BDG programme is not sufficient to identify the counterfactual. This fundamental evaluation problem can be minimized through the application of the "Conditional Difference-in-Differences" methodology employed in this study assuming that the parallel trend assumption holds. Although there is no specific way to determine if the assumption is true, its plausibility can be visually assessed by plotting the income trajectories of the treatment and control groups for the pre-treatment period [36]. However, in the absence of pre-treatment data, recent studies have employed the "Conditional Difference-in-Differences" methodology to make the parallel trend assumption more plausible by combining a propensity score matching approach with difference-in-differences (DiD) analytical technique [36]. The Conditional Difference-in-Differences approach allows for the balancing of the treatment and control groups with respect to the observed characteristics $\mathrm{X}$ making the parallel trend assumption more plausible. It is important to mention that in conducting our analysis, we also assume that there is no interference (spill overs) between members and non-members of the BDGs, such that each farmer's treatment status does not affect the potential outcomes of other farmers and that treatment is homogeneous across the BDG groups (Stable Unit Treatment Value Assumption (or SUTVA)) [37].

\subsection{The Conditional Difference-in-Differences Methodology}

The "Conditional Difference-in-Differences" methodology combines a propensity score matching approach with difference-in-differences (DiD) analysis to obtain a credible estimate of the causal effect of BDG membership on farmers' income. The approach is attractive because it can control for time-invariant unobserved heterogeneities and at the same time reduce selection bias that arises with simple comparisons $[14,16,29,38]$. Selection bias is alleviated when a treatment unit is matched individually with control units that are as similar as possible in observable characteristics that are critical to programme participation and the subsequent outcome. The DiD approach estimates the treatment effect by the change in outcome variable between the members and non-members of the BDG programme based on the matched datasets [14,16,22,39]. Smith and Todd [14] found the conditional DiD methodology to perform much better than cross-sectional methods in cases where participants and non-participants are drawn from different samples.

Suppose subscript $t$ represents the time of enrolment into the programme while subscript $k$ denotes the time period after the programme starts with $k \geq 0$ and farm $j$ belongs to the control (i.e., non-members of the BDG programme) group, while $X$ is the set 
of observable characteristics on which the members and non-members of the BDG groups are matched.

The conditional DiD estimator can be defined as presented in Equation (2). The treatment indicator in the DiD setting requires the absence of any intervention in the baseline for either group [40].

$$
\Delta \mathrm{Y}=\left(Y_{i, t+k}^{1}-Y_{i, t-1}^{0} \mid D=1, X\right)-\left(Y_{j, t+k}^{0}-Y_{j, t-1}^{0} \mid D=0, X\right)
$$

where $Y_{i, t+k}^{1}$ is the outcome (farm gross margin) for a farmer after joining the BDG and $Y_{i, t-1}^{0}$ is the outcome before joining the BDG while $Y_{j, t+k}^{0}$ and $Y_{j, t-1}^{0}$ represents the outcome for the control group after and before joining the BDG programme respectively. In our model, our base year $(t-1)$ is 2015 . This is the year preceding the setting up of the BDG groups in $2016(t)$ and our evaluation period is three years after farmers have joined the BDG groups $(t+3)$. A positive (negative) $\Delta \mathrm{Y}$ indicates an increase (decrease) in farm gross margin for the treated farms (BDG members) in comparison with the control farms (non-BDG members).

\subsection{Matching Procedure}

Matching is based on the Conditional Independence Assumption (CIA). The assumption is required to estimate the average income of the BDG members if they were not members of the BDG group. It implies that we can equate the average income of non-BDG members to those of BDG members on the condition that there exist a set of observable characteristics $X$ such that

$$
E\left(Y_{i}^{0} \mid D=1, X\right)=E\left(Y_{i}^{0} \mid D=0, X\right)
$$

Based on the above CIA assumption, the average treatment effect of membership of the BDG group with a population of size $N$ can be estimated using Equation (4).

$$
\Delta \mathrm{Y}=\frac{1}{N_{1}} \sum_{i \in\{D=1\}}\left(Y_{i}^{1}-\sum_{j \in\{D=0\}} w_{i, j} Y_{j}^{0}\right)
$$

The counterfactual farm income of non-BDG membership for a farmer who is a member of a BDG group is estimated by implementing a weight function $w_{i, j}$ in the sample of farmers who are not members of the BDG group relative to the observable characteristics $X$ of each farmer $i$. The weight function gives a higher weight to farmers that are not members of the BDG group and who have a high similarity in $X$ relative to farmers that are members of the BDG group and a lower weight when there is a low level of similarity in $X$. Based on the weight function, the potential non-BDG membership gross margin for each farmer that is a member of the BDG group are estimated based on the sample of farmers that are not members of BDG group with weights summing up to 1.

$$
\sum_{j \in\{D=0\}} w_{i, j}=1
$$

Following Equation (1) and drawing on observable information from the non-experimental datasets the average impact of the membership of the BDG programme on-farm gross margin can be estimated consistently by the difference-in-differences in means between members of the BDG programme and matched controls based on Equation (6).

$$
\Delta \mathrm{Y}=\frac{1}{N_{1}} \sum_{i \in\{D=1\}}\left(Y_{i, t+k}^{1}-Y_{i, t-1}^{0}-\left[\sum_{j \in\{D=0\}} w_{i, j} Y_{j, t+k}^{0}-\sum_{j \in\{D=0\}} w_{i, j} Y_{j, t-1}^{0}\right]\right)
$$


Rosenbaum and Rubin [13] suggest conditioning on a propensity score (propensity score matching) instead of conditioning on $X$. The propensity score is defined as the probability of participation for farm $i$ given a set $X=x_{i}$ of farm characteristics. With participation in the BDG programme serving as the endogenous variable, we estimate the conditional DiD following Villa [40] using STATA software allowing for the standard errors and $t$-values to be automatically generated. There are a variety of matching algorithms in the literature including the nearest neighbour matching, calliper matching, radius matching, stratification matching, interval matching, kernel matching and local linear matching. Generally, the selection of any one of the algorithms is mainly at the discretion of the researcher and the structure of available data [41]. In this study, we employed the non-parametric Epanechnikov kernel matching algorithm with replacement to achieve the best balancing quality among the covariates $[26,33,40]$. Previous studies by Caliendo and Kopeinig [26] have shown that matching algorithms 'with replacement' performed better in comparison to 'without replacement'. The matching with replacement algorithm was also chosen given the limitation posed by data availability such that control farms can serve more than once as a control unit. The kernel weight is calculated using a kernel function with a selected bandwidth parameter of 0.06 . In carrying out the matching, a common support requirement is implemented so that only pairs within the common support region are included in the DiD analysis $[39,40]$. Based on our review of the literature and data availability, the covariates included in the probit model used for computing the propensity scores include herd size, land area and age of the farmer. For the sheep BDG group, land type variable (Generally, farms in Northern Ireland like other parts of the UK are classified into Lowland (LL), Disadvantaged Area (DA) and Severely Disadvantaged Area (SDA). Farms classified as DA and SDA have all or most of their land within the Less Favoured Area (LFA). A holding is classified as LL if less than 50 per cent of its total area is in the LFA [42]), was also included as a categorical variable with lowland as the reference point (i.e., $\mathrm{LL}=1 ; \mathrm{DA}=2 ; \mathrm{SDA}=3$ ). However, it was not included for the dairy BGD group as most dairy farms are located in LL areas. Due to data limitations, we were not able to include more variables in the matching. Moreover, only those farmers who were in the BDG over the three year period (2016 to 2019) were included in our analyses. Although this reduces our sample size, it was necessary to ensure consistency and to ensure homogeneity, as much as possible, in our sample group.

\section{Data and Descriptive Statistics}

The study analysis used data obtained from the CAFRE Farm Business Improvement Scheme (FBIS) - Longitudinal Study benchmarking data and the Farm Business Survey (FBS) data. While data for the members of the BDG group was obtained from the FBIS benchmarking data collected annually from the members of the BDG programme (treatment group), data for non-members was obtained from the farm business survey (FBS) data collected by the Department of Agriculture, Environment and Rural Affairs (DAERA) Statistics and Analytical Services Branch [43]. The benchmarking and FBS data contain detailed information regarding the financial position of the farm business, and they are compiled using comparable accounting standards. The analysis comprised two BDG enterprise groups, namely: dairy and sheep enterprise groups. The economic performance of the farmers in respect of their membership of the BDG groups was compared based on gross margin per head. The gross margin is estimated by subtracting the total variable costs from gross farm revenue. The conditional difference-in-differences analysis was conducted separately for the dairy and sheep BDG groups.

An overview of the farm characteristics of the BDG groups stratified by treatment status is presented in Table 1 . The results of the analysis showed a statistically significant difference in farm characteristics between farmers participating in the BDG programme and the non-participants with regard to most matching variables, particularly for the dairy BDG group. For example, it can be observed in both groups that farmers in the BDGs have larger land areas, larger herd size, are younger and are the more profitable farmers. 
The higher profitability of the BDG farmers may be associated with the fact that farmers who join participatory extension programmes are more motivated to improve farm-level profitability and are therefore more likely to adopt new technologies and improved farm management practices [3]. Previous studies in the literature, for example, Davis, Nkonya, Kato, Mekonnen, Odendo, Miiro and Nkuba [30] and ref. [5] also found initial differences between participants and non-participants of participatory extension programmes.

Table 1. Descriptive statistics on characteristics of the BDG and Non-BDG Farmers, 2015.

\begin{tabular}{|c|c|c|c|c|c|c|}
\hline \multirow{2}{*}{ Variables } & \multirow{2}{*}{ Unit } & \multicolumn{2}{|c|}{ BDG Farmers } & \multicolumn{2}{|c|}{ Non-BDG Farmers } & \multirow[t]{2}{*}{ Mean Difference } \\
\hline & & Mean & SD & Mean & SD & \\
\hline Dairy Group & & $N=159$ & & $N=48$ & & \\
\hline Land area & Hectares & 55.1 & 30.7 & 42.8 & 24.3 & $12.2 * *$ \\
\hline Age of farmer & Years & 44.9 & 11.8 & 54.7 & 12.8 & $-9.8^{* * *}$ \\
\hline Size of herd & Cow numbers & 120.6 & 66.9 & 85.7 & 50.7 & $34.9^{* * *}$ \\
\hline Gross margin & $£ /$ cow & 646.1 & 206.4 & 490.7 & 194.7 & $155.4^{* * *}$ \\
\hline Milk yield & Litres per cow & 7646.1 & 1323.3 & 6366.1 & 1495.3 & $1279.9^{* * *}$ \\
\hline Sheep Group & & $N=57$ & & $N=45$ & & \\
\hline Land area & Hectares & 71.4 & 58.1 & 61.3 & 33.8 & 10.1 \\
\hline Age of farmer & Years & 46.7 & 12.2 & 54.9 & 11.8 & $-8.1^{* * *}$ \\
\hline Size of herd & Ewe numbers & 230.2 & 180.8 & 198.8 & 167.3 & 31.3 \\
\hline Gross margin & $£ /$ ewe & 53.6 & 27.8 & 30.6 & 20.2 & $22.9^{* * *}$ \\
\hline
\end{tabular}

Double and triple asterisks $\left({ }^{* *},{ }^{* * *}\right)$ indicate significance at the $5 \%$ and $1 \%$ level, respectively.

\section{Results and Discussion}

\subsection{Probit Estimates, Common Support Region and Balancing Property Check}

The parameter estimates for the first stage of the conditional difference-in-differences analysis is presented in Table 2. The probit regression model was employed to construct the propensity scores that were used for matching prior to conducting the difference-indifferences analysis. The analysis undertaken by making use of the baseline (2015) data reveals some interesting results relating to the determinants of membership of the BDG groups. For the dairy BDG group, the results of the analysis show that age and herd size were statistically significant factors influencing the decision to join the dairy BDG group. For the sheep BDG group, we found age and farm location to be statistically significant factors influencing the decision to join the BDG group.

Table 2. Probit model estimates.

\begin{tabular}{ccc}
\hline Dairy Group & Coefficient & Standard Error \\
\hline Herd size (no of dairy cows) & $0.0099^{* *}$ & 0.0044 \\
Age (years) & $-0.0408^{* * *}$ & 0.0089 \\
Land area (ha) & -0.0075 & 0.0097 \\
Constant & $2.0817^{* * *}$ & 0.4716 \\
Sheep Group & & \\
Herd size (no of ewes) & 0.0008 & 0.0009 \\
Age (years) & $-0.0372^{* * *}$ & 0.0118 \\
Land area (ha) & 0.0043 & 0.0039 \\
Disadvantage Area (DA) & -0.6417 & 0.3982 \\
Severely Disadvantage Area (SDA) & $-1.3817^{* * *}$ & 0.3287 \\
Constant & $2.3435^{* * *}$ & 0.6869 \\
\hline
\end{tabular}

Double and triple asterisks $(* * * * *)$ indicate significance at the $5 \%$ and $1 \%$ level, respectively.

The results show that relative to sheep farms on the lowland, the farmers in severely disadvantaged areas are less likely to participate in the BDG programme. This result is similar to that obtained by Hennessy and Heanue [3] who found that dairy farmers in more advantaged regions are more likely to take part in dairy discussion groups. 


\subsection{Quality of the Matching}

An observation of the balancing property of each observed covariates between the treatment and the control groups after matching showed that they are all sufficiently balanced. This reflects the effectiveness of the propensity score kernel matching as sampling bias was reduced in the initial period 2015 (before programme participation). This is verified by comparing the joint significance of all matching variables in the probit models before and after matching for both BDG groups. The initial statistically significant difference in the matching covariates for treatment and the control groups have become statistically insignificant and therefore indicating a significant reduction of the selection bias (Table 3). The implementation of the common support requirement resulted in the dropping of 9 farms that were outside the common support region in the sheep BDG and 29 farms for the dairy BDG.

Table 3. Quality of matching variables.

\begin{tabular}{|c|c|c|c|c|c|c|c|}
\hline \multirow[b]{2}{*}{ Dairy Group } & \multicolumn{3}{|c|}{ Before Matching } & \multicolumn{3}{|c|}{ After Matching } & \multirow[b]{2}{*}{$\begin{array}{c}\% \text { Reduction } \\
\text { | Bias | }\end{array}$} \\
\hline & $\begin{array}{c}\text { Treated } \\
(N=159)\end{array}$ & $\begin{array}{l}\text { Control } \\
(N=48)\end{array}$ & $\%$ Bias & $\begin{array}{c}\text { Treated } \\
(N=133)\end{array}$ & $\begin{array}{l}\text { Control } \\
(N=45)\end{array}$ & $\%$ Bias & \\
\hline Herd size (no of dairy cows) & 120.6 & 85.7 & 58.9 & 104.37 & 101.2 & 5.3 & 90.9 \\
\hline Age (years) & 44.9 & 54.7 & -80.0 & 46.9 & 46.3 & 4.8 & 94.0 \\
\hline Land area (ha) & 55.1 & 42.8 & 44.2 & 48.3 & 46.8 & 5.3 & 88.1 \\
\hline Sheep Group & $\begin{array}{l}\text { Treated } \\
(N=57)\end{array}$ & $\begin{array}{l}\text { Control } \\
(N=45)\end{array}$ & & $\begin{array}{l}\text { Treated } \\
(N=52)\end{array}$ & $\begin{array}{l}\text { Control } \\
(N=41)\end{array}$ & & \\
\hline Herd size (no of ewes) & 230.2 & 198.9 & 18.0 & 224.0 & 206.2 & 10.3 & 43.0 \\
\hline Age (years) & 46.7 & 54.9 & 67.9 & 47.5 & 47.2 & 1.9 & 97.2 \\
\hline Land area (ha) & 71.3 & 61.3 & 21.2 & 62.5 & 71.5 & -19.0 & 10.4 \\
\hline
\end{tabular}

\subsection{Impact of Membership of BDG Programme on Farm Gross Margin}

The results of the analysis using the conditional difference-in-differences approach to examine the impact of membership of the BDG groups on gross margin performance are presented in Table 4 . The results of the analysis show that membership of the dairy and sheep BDG groups has a positive and statistically significant impact on farm gross margin performance. The results showed that farmers who are members of the dairy BDG group increased their gross margin per cow by $£ 109.10$, compared to dairy farmers that are not members of the BDG programme. For members of the sheep BDG groups, participation in the BDG group resulted in a $£ 17.10$ increase in farm gross margin compared to non-membership over the three years period. This result is similar to that obtained by Läpple, Hennessy and Newman [5] in which they found a positive and statistically significant impact of membership of dairy discussion groups in Ireland on-farm gross margins. Participation in the BDG programme exposes the farmers to a wide variety and range of information and when applied on farm enhances their farm operations thus improving financial performance. Our study result also supports findings from similar research by Cawley, O'Donoghue, Heanue, Hilliard, Sheehan and Stefanou [20] and Davis, Nkonya, Kato, Mekonnen, Odendo, Miiro and Nkuba [30] conducted on the impact of participatory extension programmes on farm income, indicating that members of participatory extension groups have a significant effect on members' farm profitability. Given the current climate in which farmers are faced with a rapidly changing environment, education and training in the form of the participatory extension programme have the potential to help them understand how and what information to acquire; to make better use of information and to become innovators and early adopters of new technologies resulting in improved farm income levels. 
Table 4. Impact of BDG membership on gross margin.

\begin{tabular}{cccc}
\hline BDG Type & Gross Margin $(\boldsymbol{f} /$ Head) & Standard Error & $\boldsymbol{t}$-Value \\
\hline Dairy & $109.1^{*}$ & 58.3 & 1.87 \\
Sheep & $17.1^{* *}$ & 7.8 & 2.2 \\
\hline
\end{tabular}

* and ${ }^{* *}$ Indicate significance at the $10 \%$ and $5 \%$ levels, respectively.

\section{Conclusions}

This study analysed the impact of membership of dairy and sheep Business Development Groups (BDGs) on-farm gross margin by employing the conditional differencein-differences methodology. The approach combines a non-parametric score matching estimator with a DiD analytical technique to address the endogeneity of BDG participation. The approach which employs a kernel matching algorithm can overcome hidden bias by addressing, in a flexible way, selection on observables as well as those unobservables associated with the decision to participate in the BDG programme. Assuming that BDG participation is as good as random after controlling for observable farm characteristics and that the parallel trends assumption holds between BDG participants and non-participants, then we can interpret our results as being attributable to the causal effects of the BDG programme on farms' economic performance. Even if these assumptions are not perfectly satisfied, we argue that our estimates are the most credible possible given our nonexperimental context. The study provides robust evidence to inform policy development around the area of participatory extension programmes. Our findings reveal that the membership of the BDG groups has a statistically significant and positive impact on farm gross margin performance. The study results show that organising farmers into participatory extension groups can increase the farm business' income and contribute to the competitiveness of the farming sector. The results have practical implications for the design of participatory extension programmes for different enterprise groups. It shows that in designing participatory extension programmes for farmers, policymakers should consider the diverse characteristics of the various enterprise groups. It supports the design of efficient agricultural education and extension systems that incorporate the ideas of the farmers themselves through peer-to-peer learning, thereby maximising both the economic and social benefits accruable from such programmes.

In the interpretation of the study results, however, it should be noted that the conditional DiD methodology employed in this study is implemented on the assumption that the model contains the 'appropriate' (observable) covariates that may influence the programme effect before and after matching. However, unobservable covariates may result in different trends between the treatment and control groups, which could bias the results obtained. Despite this limitation, we consider the conditional DiD approach for programme evaluation to be a useful analytical technique in the empirical evaluation of government programmes as it provides a suitable way of dealing with potential endogeneity and treatment heterogeneity issues of intervention programmes like the BDG. It is also important to note that this study focuses solely on the economic impact. However, participation in the BDG programme can have a much wider impact including environmental outcomes from a farm production perspective. Furthermore, from a human and social perspective, there may be benefits for participants' mental health through the opportunities to engage socially with other like-minded farmers. Future studies can evaluate the inter-relationship between membership of the BDG programme and environmental indicators such as greenhouse gases and ammonia emissions as well as on social and psychological well-being.

Author Contributions: Conceptualisation, C.J., A.H.A., A.A. and M.W.; methodology, C.J., A.H.A., M.W. and A.A.; formal analysis, A.H.A.; writing-original draft preparation, A.H.A. and C.J.; writing-review and editing, A.H.A., C.J., A.A. and M.W., project administration C.J. and A.H.A. All authors have read and agreed to the published version of the manuscript.

Funding: This research was undertaken as part of the Northern Ireland Department of Agriculture, Environment and Rural Affairs Evidence and Innovation Programme (DAERA E\&I 18/1/01)—Impact 
of RDP: Evaluation of the Rural Development Programme 2014-2020, Farm Business Improvement Scheme-Longitudinal Study.

Institutional Review Board Statement: Not applicable.

Informed Consent Statement: Informed consent was obtained from all participants involved in the study.

Data Availability Statement: The data that support the findings of this study were provided solely for the purposes of evaluation under a data sharing agreement with the funders, DAERA and are not publicly available.

Conflicts of Interest: The authors declare no conflict of interest.

\section{References}

1. Jack, C.; Adenuga, A.H.; Ashfield, A.; Wallace, M. Investigating the Drivers of Farmers' Engagement in a Participatory Extension Programme: The Case of Northern Ireland Business Development Groups. Sustainability 2020, 12, 4510. [CrossRef]

2. Fakayode, S.B.; Adenuga, A.H.; Yusuf, T.; Jegede, O. Awareness of and demand for private agricultural extension services among small-scale farmers in Nigeria. J. Agribus. Rural. Dev. 2016, 4, 521-531.

3. Hennessy, T.; Heanue, K. Quantifying the Effect of Discussion Group Membership on Technology Adoption and Farm Profit on Dairy Farms. J. Agric. Educ. Ext. 2012, 18, 41-54. [CrossRef]

4. King, B.; Fielke, S.; Bayne, K.; Klerkx, L.; Nettle, R. Navigating shades of social capital and trust to leverage opportunities for rural innovation. J. Rural. Stud. 2019, 68, 123-134. [CrossRef]

5. Läpple, D.; Hennessy, T.; Newman, C. Quantifying the Economic Return to Participatory Extension Programmes in Ireland: An Endogenous Switching Regression Analysis. J. Agric. Econ. 2013, 64, 467-482. [CrossRef]

6. Tamini, L.D. A nonparametric analysis of the impact of agri-environmental advisory activities on best management practice adoption: A case study of Québec. Ecol. Econ. 2011, 70, 1363-1374. [CrossRef]

7. Woodhill, J. Innovating Innovation: A Perspective on the Evolution of Innovation Processes in Agriculture and Rural Development. In Dynamics of Rural Innovation: A Primer for Emerging Professionals; Pybrun, R., Woodhill, J., Eds.; LM Publishers: Arnhem, The Netherlands, 2014; pp. 15-30.

8. Black, A.W. Extension theory and practice: A review. Aust. J. Exp. Agric. 2000, 40, 493-502. [CrossRef]

9. Esparcia, J. Innovation and networks in rural areas. An analysis from European innovative projects. J. Rural. Stud. 2014, 34, 1-14. [CrossRef]

10. DAERA. United Kingdom-Rural Development Programme (Regional)-Northern Ireland; Department of Agriculture Environment and Rural Affairs, Ed.; Department of Agriculture Environment and Rural Affairs: Belfast, Northern Ireland, 2021; Volume 9, p. 1052.

11. Northern Ireland Assembly. Farm Business Improvement Scheme: Department of Agriculture, Environment and Rural Affairs; Committee for Agriculture, Environment and Rural Affairs, Rural, A., Eds.; Northern Ireland Assembly: Belfast, Northern Ireland, 2016.

12. Loi, M.; Rodrigues, M. A note on the impact evaluation of public policies: The counterfactual analysis. MPRA 2012, 42444,54 .

13. Rosenbaum, P.R.; Rubin, D.B. The Central Role of the Propensity Score in Observational Studies for Causal Effects. Biometrika 1983, 70, 41-55. [CrossRef]

14. Smith, J.A.; Todd, P.E. Does matching overcome LaLonde's critique of nonexperimental estimators? J. Econom. 2005, 125, 305-353. [CrossRef]

15. Heckman, J.; Hohmann, N.; Smith, J.; Khoo, M. Substitution and Dropout Bias in Social Experiments: A Study of an Influential Social Experiment*. Q. J. Econ. 2000, 115, 651-694. [CrossRef]

16. Heckman, J.; Ichimura, H.; Todd, P.E. Matching as an Econometric Evaluation Estimator: Evidence from Evaluating a Job Training Programme. Rev. Econ. Stud. 1997, 64, 605-654. [CrossRef]

17. Rossi, P.H.; Freeman, H.E.; Lipsey, M.W. Evaluation. A systematic Approach, 7th ed.; Sage Publications, Inc.: New York, NY, USA, 2004.

18. Abdallah, W.; Goergen, M.; O'Sullivan, N. Endogeneity: How Failure to Correct for it can Cause Wrong Inferences and Some Remedies. Br. J. Manag. 2015, 26, 791-804. [CrossRef]

19. Akobundu, E.; Alwang, J.; Essel, A.; Norton, G.W.; Tegene, A. Does Extension Work? Impacts of a Program to Assist LimitedResource Farmers in Virginia. Rev. Agric. Econ. 2004, 26, 361-372. [CrossRef]

20. Cawley, A.; O'Donoghue, C.; Heanue, K.; Hilliard, R.; Sheehan, M.; Stefanou, S. The Impact of Extension Services on Farmlevel Income: An Instrumental Variable Approach to Combat Endogeneity Concerns. Appl. Econ. Perspect. Policy 2018, 40, 585-612. [CrossRef]

21. Feder, G.; Murgai, R.; Quizon, J.B. Sending Farmers Back to School: The Impact of Farmer Field Schools in Indonesia. Rev. Agric. Econ. 2004, 26, 45-62. [CrossRef]

22. Imbens, G.W.; Wooldridge, J.M. Recent Developments in the Econometrics of Program Evaluation. J. Econ. Lit. 2009, 47, 5-86. [CrossRef]

23. Bascle, G. Controlling for endogeneity with instrumental variables in strategic management research. Strateg. Organ. 2008, 6, 285-327. [CrossRef] 
24. Wooldridge, J.M. Econometric Analysis of Cross Section and Panel Data; MIT Press: Cambridge, MA, USA, 2002.

25. Läpple, D.; Hennessy, T. Assessing the Impact of Financial Incentives in Extension Programmes: Evidence From Ireland. J. Agric. Econ. 2015, 66, 781-795. [CrossRef]

26. Caliendo, M.; Kopeinig, S. Some Practical Guidance for the Implementation of Propensity Score Matching. J. Econ. Surv. 2008, 22, 31-82. [CrossRef]

27. Adenuga, A.; Omotesho, O.; Ojehomon, V.; Diagne, A.; Ayinde, O.; Arouna, A. Adoption of Improved Rice Varieties and its Impact on Multi-Dimensional Poverty of Rice Farming Households in Nigeria. Appl. Trop. Agric. 2016, 21, $24-32$.

28. Imbens, G.W.; Angrist, J.D. Identification and Estimation of Local Average Treatment Effects. Econometrica 1994, 62, 467-475. [CrossRef]

29. Udagawa, C.; Hodge, I.; Reader, M. Farm Level Costs of Agri-environment Measures: The Impact of Entry Level Stewardship on Cereal Farm Incomes. J. Agric. Econ. 2014, 65, 212-233. [CrossRef]

30. Davis, K.; Nkonya, E.; Kato, E.; Mekonnen, D.A.; Odendo, M.; Miiro, R.; Nkuba, J. Impact of Farmer Field Schools on Agricultural Productivity and Poverty in East Africa. World Dev. 2012, 40, 402-413. [CrossRef]

31. Rose, D. The impact of active labour market policies on the well-being of the unemployed. J. Eur. Soc. Policy 2019, 29, 396-410. [CrossRef]

32. Bakucs, Z.; Fertô, I.; Benedek, Z. Success or waste of taxpayer money? Impact assessment of rural development programs in Hungary. Sustainability 2019, 11, 2158. [CrossRef]

33. Su, D.; Chen, Y.C.; Gao, H.X.; Li, H.M.; Chang, J.J.; Jiang, D.; Hu, X.M.; Lei, S.H.; Tan, M.; Chen, Z.F. Effect of integrated urban and rural residents medical insurance on the utilisation of medical services by residents in China: A propensity score matching with difference-in-differences regression approach. BMJ Open 2019, 9, e026408. [CrossRef]

34. Rubin, D.B. Estimating Causal Effects of Treatments in Randomized and Nonrandomized Studies. J. Educ. Psychol. 1974, 66, 688-701. [CrossRef]

35. Buscha, F.; Maurel, A.; Page, L.; Speckesser, S. The Effect of High School Employment on Educational Attainment: A Conditional Difference-in-Differences Approach. Oxf. Bull. Econ. Stat. 2012, 74, 380-396. [CrossRef]

36. Gebel, M.; Voßemer, J. The impact of employment transitions on health in Germany. A difference-in-differences propensity score matching approach. Soc. Sci. Med. 2014, 108, 128-136. [CrossRef]

37. Armstrong, C.S.; Kepler, J.D. Theory, research design assumptions, and causal inferences. J. Account. Econ. 2018, 66, 366-373. [CrossRef]

38. Pufahl, A.; Weiss, C.R. Evaluating the effects of farm programmes: Results from propensity score matching. Eur. Rev. Agric. Econ. 2009, 36, 79-101. [CrossRef]

39. Dehejia, R.H.; Wahba, S. Propensity Score-Matching Methods For Nonexperimental Causal Studies. Rev. Econ. Stat. 2002, 84, 151-161. [CrossRef]

40. Villa, J.M. Diff: Simplifying the Estimation of Difference-in-differences Treatment Effects. Stata J. 2016, 16, 52-71. [CrossRef]

41. Kirchweger, S.; Kantelhardt, J. The dynamic effects of government-supported farm-investment activities on structural change in Austrian agriculture. Land Use Policy 2015, 48, 73-93. [CrossRef]

42. DAERA. Statistical Review of Northern Ireland Agriculture 2020; Policy, Economics and Statistics Division, Department of Agriculture, Environment and Rural Affairs: Belfast, Northern Ireland, 2021; p. 96.

43. Adenuga, A.H.; Davis, J.; Hutchinson, G.; Patton, M.; Donnellan, T. Analysis of the effect of alternative agri-environmental policy instruments on production performance and nitrogen surplus of representative dairy farms. Agric. Syst. 2020, 184, 102889. [CrossRef] 